\title{
An Astronomical Basis for the Myth of the Solar Hero
}

\section{Robin Heath*}

\section{Introduction}

Our increasing knowledge of the megalithic culture of the British Isles in the 2nd and 3rd millennia $\mathrm{BCE}$ tends to confirm the proposition that megalithic astronomers measured celestial positions with considerable accuracy. The evidence indicates that they understood the 18.6 year nodal period and the moon's nine minute declination wobble. ${ }^{1}$ They also had sufficient geometrical ability to re-proportion spacings between lines, divide circles into whole number polygons and divide lines into equal integer spacings. ${ }^{2}$ We should therefore ask whether there is evidence of such early astronomy in the numbers which recur in certain myths. The following should be viewed as preliminary arguments.

\section{The Thirty-Three Year Cycle}

If our interest is megalithic astronomy then we should search for relevant evidence in the myths of the British Isles. One of the most recurrent numbers in the stories of the Tuatha de Danaan who, according to tradition, inhabited Ireland before 1,500 BCE, is thirty-three. ${ }^{3}$ We are told, for example, that the first battle of Mag Tuired was fought by the saviour-hero Lug and thirty-two other leaders. In the same vein, Nemed, another hero, reached Ireland with only one ship, while thirty-three were lost on the way; Cuchulainn slays thirty-three of the Labriads in the Bru battle whilst a late account of the second battle of Mag Tuired names thirty-three leaders of the Fomorii, thirty-two plus their highest king. ${ }^{4}$

This material contains one clear and obvious common theme. Repeatedly, it reinforces an originally oral message which told the knowing listener to look to the number thirty-three as something relevant to a hero, a saviour. In his analysis of the Welsh White Book of Rhydderch, N.L.Thomas writes that 'Both three and eleven were equally symbolic, the multiplicand thirty-three particularly so. It has frequently been used to imply supra-human attributes, regal authority and deification. ${ }^{5}$

\footnotetext{
* Megalithic Tours, Cwm Degwel, St.Dogmael's, Cardigan, SA43 3JF, UK.
} 
We find evidence of the astronomical and mythical significance of the thirty three year cycle in other cultures. Perhaps the best known example is found in the tradition that Christ began his ministry at age thirty and was crucified at age thirty three. ${ }^{6}$ The solar tradition in early Christianity is well-recorded, with the widespread identification of Christ with Helios and the fixing of Christmas to coincide with the festival of Sol Invictus, a few days after the winter solstice, and Easter close to the spring equinox. ${ }^{7}$ It is partly on the basis of such evidence, together with the argument that epic myths such as those of Gilgamesh and Hercules represent solar cycles, that modern comparative mythology has produced the notion of the solar hero. ${ }^{8}$ I am arguing that the numerical evidence in the Celtic tales provides astronomical evidence that they too could be considered solar heroes.

\section{Megalithic Astronomy and the Solar Cycle}

Many megalithic standing stones have been shown to relate to extreme Sun and Moon rising and setting azimuths against the local horizon. While the link at some sites is tenuous it is beyond doubt in others, as for example at Stonehenge. ${ }^{9}$ The practical solar year is 365 days long. I say practical because most reference books claim that there are 365 and a quarter days in the year, a confusion with the Earth's orbital period around the Sun. Every fourth year an extra day slips in to make it 366 days. In four years there are thus 1461 days. It is fairly easy to observe the Sun's behaviour and thereby measure this number.

An equinoctial Sunrise marker, of which many still exist in the British uplands will, each year, deliver the vernal equinox sunrise from a slightly different position on the horizon. The 'quarter day effect' means that the Sun, each year, is displaced about a quarter of a degree from the marker stone. During three years of observation, the Sun appears to be slipping every more away from the alignment until, at the fourth year, two remarkable and very observable things happen simultaneously: the Sun rises once more very close to the marker stone, whence the day count the tally - for the year is found to be 366 and not 365 days. Observation does not stop there, and a good human eye can detect much more minuscule angular changes than a quarter of a degree from watching sunrises. ${ }^{10}$ The truth about solar year measurements carried out at the equinox is that the result is always 365 days unless sustained observations are conducted over many years. In that case the result is 365.25 days, a figure which, under optimum conditions could be reached after four years (see Figure 1). ${ }^{11}$ This figure is within eleven minutes of 
time of that for the tropical year (365.24219 mean solar days) and is almost identical to that for the civil, calendar, year (365.2425 mean solar days).

\section{Figure 1}

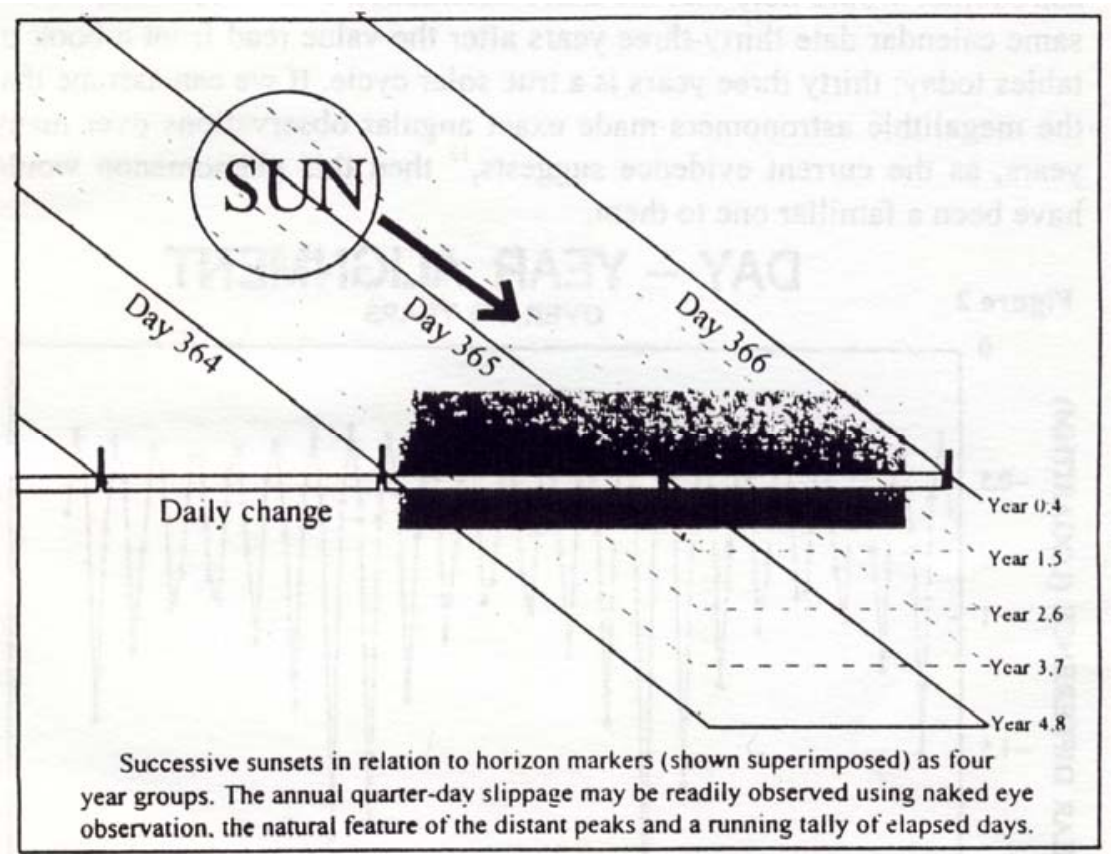

For longer time periods something else happens. Every once in a whole number of years the chance arises to measure the year with even greater precision. This can be achieved by observing certain key years when, once again, the Sun rises precisely behind the foresight - be this a stone marker or a distant mountain peak - in other words, a perfect repeat solar cycle.

What we may assume, courtesy of their enduring architecture, is that the megalithic astronomers could have readily evaluated the length of the solar year to two decimal places. They could accomplish this by marking 1461 equal lengths on a rope - the tally count of days in four years - and then folding it in half twice to obtain 365.25 . The 1461 day tally is a 
6 A Possible Astronomical Basis for the Myth of the Solar Hero

given, gleaned from simple observation and tally counting over four years.

After thirty-three years one can observe an exact repeat of the original equinoctial rising behind the marker stone (See Table 1, Figure 2). To a megalithic astronomer, this same phenomenon would have translated as an exact repeat rising (or setting) behind a marker, whilst a modern astronomer would note that the Sun's declination will be identical on the same calendar date thirty-three years after the value read from a book of tables today; thirty three years is a true solar cycle. If we can assume that the megalithic astronomers made exact angular observations over many years, as the current evidence suggests, ${ }^{12}$ then this phenomenon would have been a familiar one to them.

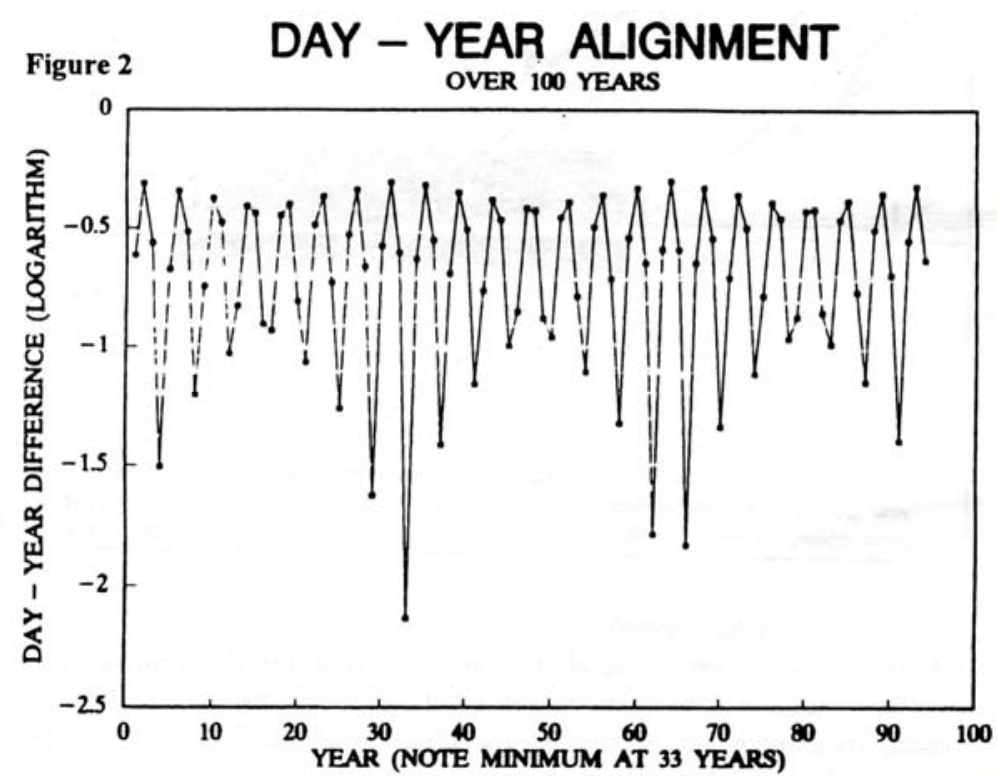

The vertical axis indicates the error from 364.242 days plotted on a logarithmic scale. The base line, 2.5 , represents the minimum deviation. The horizontal axis indicates years from 0 to 100 . This clearly indicates the thirty three year pattern. Diagram courtesy of Nick Kollerstrom.

However one interprets the data, this presents a possible astronomical source to the use of the number thirty three in heroic myths. Thus when Christ's resurrection occurs at age thirty-three, witnessed as it was at 
sunrise, we may be faced with a sophisticated astronomical/calendar metaphor. Even the rolling away of the stone to reveal the resurrected saviour may plausibly be argued to represent the emergence of the Sun from behind a stone marker, inaugurating another thirty three year cycle. $^{13}$

\section{Conclusion}

Contemporary archaeology has established the astronomical sophistication of the megalith builders to a previously unsuspected level. So far the arguments, naturally enough, have rested primarily on the archaeological record. However, a second line of argument may be derived from the mythical record, even though we have to account for the problem that the written sources are necessarily of a much later date than the stone remains. It is clear that myth may provide evidence of ancient astronomical knowledge, while astronomy may also provide an additional view of ancient myths.

\section{Postscript: The Dresden Codex}

Interestingly, we can find the solar cycle of thirty-three years within other cultures, such as the Mayan. I draw attention to this as additional evidence that thirty three-year cycles may have been apparent to early astronomers. The Dresden Codex, a collection of divinatory almanacs mostly tied to the 260 day divinatory cycle, contains eclipse timings compiled by the Maya and runs for almost 33 years. ${ }^{14}$ This tabular codex abruptly finishes after 32 years and 270 days and the reason for its length is understood to be connected with the fact that 46 sacred periods of 260 days tally with this period. ${ }^{15}$ However, it is also evident that after this time frame, which corresponds to 405 lunations, the Sun will meet the lunar node axis and produce an eclipse. In other words, 405 lunations is an eclipse cycle; after 32 years and 270 days, the nodes will have made one and three quarter revolutions whilst the Sun has made 32 and three quarter revolutions of the ecliptic, the result being that the Sun meets one of the nodes, resulting in an eclipse. ${ }^{16}$ As the Dresden Codex is in part a document about eclipses, there was thus no real need to continue the tabulation to 33 years in order to complete the niceties of the evidently known solar cycle of thirty-three years, 405 lunations is the last eclipse possible within this cycle. It is therefore reasonable to infer that the codex recognises the importance of the 33 year solar cycle and that the Maya were familiar with it. 
8 A Possible Astronomical Basis for the Myth of the Solar Hero

Table 1.

\begin{tabular}{|c|c|c|c|}
\hline \multicolumn{4}{|c|}{ Important Solar Returns behind a horizon alignment } \\
\hline $\begin{array}{l}\text { Numbe } \\
\text { of yea }\end{array}$ & Days & $\begin{array}{l}\text { Time Difference } \\
\text { from whole number }\end{array}$ & $\begin{array}{l}\text { Angular error from original } \\
\text { solar observation }\end{array}$ \\
\hline 4 & $1,460.968$ & 45 minutes & $1 \mathrm{~min} .30 \mathrm{sec}$ \\
\hline 21 & $7,670.086$ & 124 minutes & $3 \mathrm{~min} .42 \mathrm{sec}$. \\
\hline 33 & $12,052.992$ & 10.7 minutes & 0 min. 18 sec. \\
\hline 62 & $22,645.016$ & 23.53 minutes & 0 min. $36 \mathrm{sec}$. \\
\hline \multicolumn{4}{|c|}{$\begin{array}{l}\text { The Tropical Solar Year is } 365.242199 \text { days in length. Multiply this by whole } \\
\text { numbers (of years) and look for products where the fractional part of the result } \\
\text { tends towards zero or one. There are several contenders, shown above. } \\
\text { Consecutive years contain an angular error of one quarter ( } 15 \text { minutes) of a } \\
\text { degree. The Daily angular sunrise change along the horizon in Southern Britain } \\
\text { at the equinox is over } 0.7 \text { degree. This is considerably more than one solar disc } \\
\text { diameter (about } 0.6 \text { degree). }\end{array}$} \\
\hline
\end{tabular}

\section{References}

1. Alexander Thom, Megalithic Sites in Britain, (Oxford, Oxford University Press, 1967, pp 59, 165. Thom reckoned that good observation can detect angular changes as small as 2.5 minutes of arc (correspondence from Archie Thom to the author, 1994). John E.Wood, Sun, Moon and Standing Stones, (Oxford, Oxford University Press, 1980) wrote that 'the Temple Wood observatory shows inherent accuracies of declination measurement to around one hundredth of a degree'.

2. Wood, Sun, Moon, pp 36-56

3 The best source for the early myths is the Royal Irish Academy's edition of The Book of Leinster, 1880, a facsimile of the Leabar na Nuachonghbhala (also sometimes known as The book of Glendalough). This contains the earliest known version of the Leabhar Gabhala, the 'book of invasions', the primary source for the stories of the Tuatha de Danaan.. The most reliable version of this work is Lebor Gabala Erenn: Book of the Taking of Ireland, ed. R.A.S.MacAlister, Irish Text Society, 5 vols, 1938, 1939, 1940, 1941, 1954.

4. N.L.Thomas, Irish Symbols of 3,500 BC (Mercia Press, Cork, 1988), p 83.

5. Thomas, Irish Symbols, p 76. For The White Book of Rhydderch see Llyfr Gwyn Rhydderch (The White Book of Rhydderch), with an introduction by T.M.Jones, (University of Wales Press, Cardiff, 1973, reprint of the 1907 edition edited by J.Gwenogvryn Evans) The original manuscript is National Library of Wales MSS Peniarth 4. Also see Rees, Alwyn and Brinley, Celtic Heritage (Thames and Hudson, London, 1961), pp 200 f., 318 ff., 338. Although The White Book of Rhydderch is dated to 1300-25, like other similar texts, it is widely believed to represent the written account of a much earlier oral tradition.

Culture and Cosmos 
6. Luke 3.23, Acts 2, record that Christ's ministry began at age thirty.

7. The earliest reference to the celebration of Christmas on Sol Invictus, December 25, is the Philocalian Calendar of 336. There are different formulae establishing the celebration of Easter. The standard has become the Roman version: Easter Sunday is the first Sunday after the full moon following the spring equinox. See also Henry Chadwick, The Early Church, Harmondsworth, Middlesex, for discussion of Christian reverence for the sun in the 1 st-3rd centuries.

8. The concept of the solar hero has been particularly popularized by the Jungians. Jung wrote that 'It is not enough for the primitive to see the sun rise and set; this external observation must at the same time be a psychic happening: the sun in its course must represent the fate of a god or hero who, in the last analysis, dwells nowhere except in the soul of man'; C.G.Jung, 'Archetypes of the Collective Unconscious', Collected Works, Vol. 9, part 1, p 6, trans F.R.C.Hull (Routledge and Kegan Paul, London, 1959).

9. For Stonehenge see Hugh Thurston, Early Astronomy (New York 1994), pp 45-55.

10. Thom, Megalithic Sites, p 108

11. Norman Lockyer argued that simple observation was sufficient to establish these figures: 'Had ignorance led to the establishment of a year of 360 days, yet experience would have led to its rejection in a few years...If observations of the Sun at solstice or equinox had been alone made use of, the true length of the year would have been determined in a few years'. Norman Lockyer, The Dawn of Astronomy, (Cambridge University Press, 1894) pp 245-6, reprint MSI, 1964.

12. At Loughcrew, in Ireland, Cairn F, Stone C1, there are a set of 62 inscribed markers, whilst nearby, at Fourknocks Passage, one may count three columns of eleven chevrons, totalling 33, picked onto a stone. See N.L.Thomas, Irish Symbols, p 73.

13. Matthew 28:1, 'as it began to dawn, towards the first day of the week'. In first century Greek astrology the first day of the week, and the first hour of the first day, were ruled by the Sun. If we can interpret the astronomical features of the resurrection story as an allegory of the solar cycle, then Mary, as the mother, represents the origin of the process, in other words the first measurement or alignment with the stone marker thirty three years previously. To extend the allegory, the stone blocking the tomb, the entrance to the underworld, rolls away revealing the resurrected form and his entrance back into the visible world.

14. See Floyd Lounsbury's paper in the Dictionary of Scientific Biography, Vol 15, supplement 1, Charles Gillespie general editor (Charles Scribener's Sons, New York)

15. Evan Hadingham, Early Man and the Cosmos, William Heinemann (London 1983), p 223. See also Anthony Aveni, Skywatchers of Ancient Mexico, (University of Texas, 1980).

16. See Thurston, Early Astronomy, p 201. 